\title{
Minor Stroke may not be a Mild Stroke
}

\author{
Leonard LL Yeo ${ }^{1}$, Prakash R Paliwal ${ }^{1}$ and Vijay K Sharma ${ }^{1,2^{*}}$ \\ ${ }^{1}$ Division of Neurology, National University Hospital, Singapore \\ ${ }^{2}$ Yong Loo Lin School of Medicine, National University of Singapore, Singapore
}

*Corresponding author: Vijay K Sharma, Division of Neurology, Department of Medicine, National University, Hospital5 Lower Kent Ridge Road, Singapore, Tel: 65-67724126; Fax: 65-68723566; E-mail: drvijay@singnet.com.sg

Received date: May 12, 2014, Accepted date: May 14, 2014, Published date: May 20, 2014

Copyright: (c) 2014 Leonard LL Yeo, et al. This is an open-access article distributed under the terms of the Creative Commons Attribution License, which permits unrestricted use, distribution, and reproduction in any medium, provided the original author and source are credited.

Keywords: Acute ischemic stroke; Intracranial collaterals; Cerebral perfusion

\section{Minor Strokes may not be Milder}

Intravenously administered tissue plasminogen activator (IV-tPA) remains the only approved drug therapy for achieving arterial recanalization in patients with acute ischemic stroke (AIS). However, numerous contraindications need to be carefully excluded before initiating the thrombolytic therapy [1]. Some of these contraindications are based on expert opinions and not founded in good science.

One important contraindication for withholding IV thrombolysis is in patients presenting with mild or minor stroke. The benefits of IV thrombolysis in this subset of AIS patients are not clear. Accordingly, patients presenting with mild stroke, especially when showing rapid clinical improvement, are often excluded from systemic thrombolysis. Although, it was not explicitly mentioned as a contraindication, the pivotal NINDS trial included only 58 patients with mild strokes. Interestingly, 2971 patients with mild or rapidly improving strokes were excluded from thrombolysis [2]. At that time the investigators most likely believed that the mild symptoms were unlikely to result in poor outcomes and risk-benefit ratio of IV-tPA might be too high. However, subsequent studies provided contradictory results. In the American Heart Association "get with the guidelines" study of 1092 hospitals comprising of 93,517 patients arrivingto the hospital within 2 hours, 29,200 (31\%) were not treated with IV-tPA solely because of mild/improving stroke. It is important to note that $28.3 \%$ of these nonthrombolysed cases could not be discharged to their home and $28.5 \%$ could not walk unaided at the time of hospital discharge [3]. Similar unfavourable outcomes were reported from many other studies when patients with mild AIS were not thrombolysed [4,5]. A study on mild stroke patients showed that a proportion of patients with mild strokes or having rapid neurological improvement, if excluded from thrombolysis because of a 4-point improvement in their NIHSS scores, develop subsequent neurological worsening [6]. These figures strongly suggest that the 'mild' strokes should not be considered as 'benign'.

One of the main reasons for the controversy regarding thrombolysis in mild AIS is the lack of a clear definition. Fischer and his co-authors tried to define the criteria for a mild or minor stroke. According to them it should be non-disabling acutely and have favourable short to medium term outcomes, be valid for various types of stroke patients, be valid for qualitative and quantitative dimensions, be useable in daily practice and should differentiate itself from TIA definitions [7]. Despite providing some clarity this definition is not easily translatable into a definition that can be easily used in a clinical setting.
The American Heart Association stroke guideline has loosely defined mild AIS as 'minor and isolated symptoms that are not presently potentially disabling" [1]. This terminology is fraught with uncertainty as even though the vast majority of patients with potentially disabling symptoms will have NIHSS scores $\geq 4$, certain patients, such as those with gait disturbance, isolated aphasia, or isolated hemianopia, may have potentially disabling symptoms although their NIHSS score is just [2]. Despite the dearth of good evidence, this is an important question as there is an economic element to this debate. In a study by khatri, she showed that treating mild strokes with IV-tPA could save up to \$200 million in the United States alone [8]. In a recent meta-analysis of previous published studies, we have shown that patients with mild strokes derive benefit from intravenous thrombolysis without any significant increase in mortality [9].

While we await more definitive randomised clinical trials, up till the present, studies that have looked at mild strokes are limited by the number of patients. Moreover the controls that are used for comparison have frequently been extrapolated from previous trials which may not be representative of the outcomes that can be achieved with modern treatment. Current IV thrombolysis guidelines for mild or minor acute stroke are in need of revision to support the clinician who may feel that IV-tPA may benefit his patient but are limited as the situation falls outside the published guidelines. Violating the license for IV-tPA may not be legally viable in many countries. Therefore, the guidelines, which may not be based on evidence, should be reevaluated as new evidence makes itself available.

\section{References}

1. Adams HP Jr, del Zoppo G, Alberts MJ, Bhatt DL, Brass L et al. (2007) American Heart Association; American Stroke Association Stroke Council, Clinical Cardiology Council, Cardiovascular Radiology and Intervention Council, and the Atherosclerotic Peripheral Vascular Disease and Quality of Care Outcomes in Research Interdisciplinary Working Groups. Guidelines for the early management of adults with ischemic stroke: a guideline from the American Heart Association/American Stroke Association Stroke Council,Clinical Cardiology Council, Cardiovascular Radiology and Intervention Council, and the Atherosclerotic Peripheral Vascular Disease and Quality of Care Outcomes in Research Interdisciplinary Working Groups: the American Academy of Neurology affirms the value of this guideline as an educational tool for neurologists. Stroke 38: 1655-1711.

2. (1995) Tissue plasminogen activator for acute ischemic stroke. The National Institute of Neurological Disorders and Stroke rt-PA Stroke Study Group. N Engl J Med 333: 1581-1587.

3. National Institute of Neurological Disorders Stroke rt-PA Stroke Study Group (2005) Recombinant tissue plasminogen activator for minor strokes: the National Institute of Neurological Disorders and Stroke rt-PA Stroke Study experience. Ann Emerg Med 46: 243-252. 
Citation: Yeo LL, Paliwal PR, Sharma VK (2014) Minor Stroke may not be a Mild Stroke. Brain Disord Ther 3: e111. doi:10.4172/2168-975X. $1000 \mathrm{e} 111$

Page 2 of 2

4. Smith EE, Fonarow GC, Reeves MJ, Cox M, Olson DM et al. (2011) Outcomes in mild or rapidly improving stroke not treated with intravenous recombinant tissue-type plasminogen activator. Stroke 42: 3110-3115.

5. Willey JZ, Khatri P, Khoury JC, Merino JG, Ford AL, et al. (2013) Variability in the use of intravenous thrombolysis for mild stroke: experience across the SPOTRIAS network. J Stroke Cerebrovasc Dis 22: 318-322.

6. Rajajee V, Kidwell C, Starkman S, Ovbiagele B, Alger JR, et al. (2006) Early MRI and outcomes of untreated patients with mild or improving ischemic stroke. Neurology 67: 980-984.
7. Fischer U, Baumgartner A, Arnold M, Nedeltchev K, Gralla J, et al. (2010) What is a minor stroke? Stroke 41: 661-666.

8. Khatri P, Khoury JC, Alwell K, Moomaw CJ, Kissela BM et al. (2011) The public health impact of an effective acute treatment for mild ischemic strokes. Stroke 42: e66.

9. Yeo LLL, Ho RC, Sharma VK (2014) Intravenous thrombolysis is beneficial in mild ischemic strokes: A meta-analysis. J Stroke Cerebrovasc Dis (in press). 